\title{
Rasgos autobiográficos en Rito de iniciación de Rosario Castellanos
}

\author{
Gerardo Bustamante Bermúdez \\ Facultad de Filosofía y Letras, UNAM
}

Toda literatura es autobiográfica, finalmente. Todo es poético en cuanto nos confiesa un destino, en cuanto nos da un vislumbre de él.

Jorge Luis Borges

Creo que toda literatura es autobiográfica; tiene todo que ver con la vida de un autor, a pesar de que no tiene nada que ver con ella.

Rosario Ferré

En 1964, año en que Rosario Castellanos publicaba Los convidados de agosto, anunció en una conferencia en Bellas Artes la escritura de Rito de iniciación (1997). Cuatro años más tarde, en una entrevista con Luis Adolfo Domínguez, la calificó de pedante y malograda: “...el libro fue saliendo un poco al aventón. Un día escribía yo una página, según mi estado de humor... según las influencias últimas que estaba recibiendo de mis novelas anteriores. Al día siguiente quería borrar todo lo anterior y hacía algo totalmente distinto. Creo que se salvarían, de esa novela que tiene diez capítulos, si acaso dos..." (Domínguez: 22).

En 1995, el Instituto Nacional de Bellas Artes, en coordinación con la Biblioteca México prepararon el "Homenaje Nacional a Rosario Castellanos" que consistió entre otras actividades, en una exposición titulada "Materia memorable" que fue expuesta de octubre a noviem- 
bre de ese año en la Biblioteca México. Cuenta Eduardo Mejía en sus comentarios a Rito de iniciación, que por esas fechas venció el alquiler de un piso que Castellanos ocupaba como bodega y es entonces cuando Gabriel Guerra - hijo de la autora- decide recoger todos los objetos de su madre. En la revisión de los materiales, Eduardo Mejía descubre las cuatrocientas páginas que "[Rosario] había guardado cariñosamente" (Mejía: 382).

Rito de iniciación es una novela completamente diferente a lo que la autora había publicado hasta entonces. Si bien es cierto que con Los convidados de agosto, la narrativa de Castellanos entra en una etapa de transición entre los espacios de provincia y los citadinos: Balún Canán (1957) y Oficio de tinieblas (1962), hay que apreciar que con Rito..., la autora privilegia la iniciación-descubrimiento por parte de Cecilia, la protagonista de la narración. Algunos críticos han emparentado a esta novela con la "nouvelle roman" o antinovela francesa y, aunque la intención de la autora no era la imitación de los modelos estilísticos europeos, sí utiliza el recurso de la fragmentación. Este fue uno de los aspectos que a algunos lectores del manuscrito les hizo mostrar su rechazo hacia la novela, razón por la cual la autora decidió no publicarla.

El planteamiento temático de Rito de iniciación es el siguiente: Cecilia, una joven de provincia, llega a la ciudad de México a finales de los años cuarenta para estudiar una carrera universitaria. En la capital, tiene que adaptarse y optar entre el rechazo al medio intelectual frívolo de la Facultad de Filosofía y Letras, o la aceptación de las reglas del medio estudiantil pseudointelectual; también tiene que aprender a vivir el fracaso amoroso y frente a esto, decide iniciarse en la vocación literaria. El renunciamiento / iniciación en Cecilia, la coloca como una marginal; al desprenderse de sus fantasmas familiares, amorosos, intelectuales y sociales, decide luchar por una vocación literaria, aunque en el fondo se advierta un fracaso personal y doloroso en el futuro.

Los personajes que aparecen en las páginas de esta novela son tan numerosos como los de la narrativa anterior de Castellanos: unos padres de los que se refiere llevan una relación malsana, una tía solterona que sale del espacio provinciano para no sentirse tan humillada por la sociedad, un grupo de jóvenes arrogantes que se consideran a sí mismos los futuros intelectuales del país, un escritor misántropo que vive enclaustrado en su casa acompañado de su hermana — una solterona dominada por él-, un grupo de escritoras fracasadas a las que la auto- 
ra ridiculiza y una joven que ve en la escritura una forma de realización femenina y una profesión.

Hablar de "escritura autorreferencial" —ya sea a través del género autobiográfico o de la ficción- lleva al lector a la búsqueda de un paratexto "real" sobre la vida del autor y contrastar lo real con lo literario. La autobiografía como escritura del "yo" tiene por objeto hacer público lo privado, aunque de manera novelada. La "autografía" (término propuesto por Jean Molino y retomado por Rolf Ebernez y otros críticos), se basa en el individualismo del autor que a través de la memoria y la palabra escrita, manifiesta algunos pasajes de su vida. La autobiografía es un relato de vida que se construye desde el presente a partir de una necesidad personal por parte del autor por recuperar un pasado y darlo a conocer, ya sea a través de una "autobiografía pura", o por medio de la "novela autobiográfica" considerada como un disfraz del yo-autor en el narrador-personaje. Philippe Lejeune define la autobiografía como un "relato retrospectivo en prosa que una persona real hace sobre su propia existencia, poniendo el acento en su vida individual, particularmente en la historia de su personalidad" (1975: 19; la traducción es mía).

La idea generalmente aceptada sobre la autobiografía es que el autor es una persona madura cuyo discurso personal está asociado a una conciencia igualmente madura. Dice Carmen Heuser que los recuerdos en la autobiografía "sólo pueden ser una ficción teñida de verosimilitud, cada hecho, cada instante [...] atraviesan el propio imaginario, y en él se construye como recuerdo" (99). La escritura autobiográfica supone una búsqueda/regreso a la interioridad de una vida, a la reelaboración temporal de acontecimientos significativos, recuperados y escritos por el autor. Règine Robin ha propuesto el termino "autoficción” para referirse a la escritura de ciertos autores que con plena conciencia, deciden hacerse a sí mismos un relato, por lo que el sujeto de la enunciación pasa a ser el sujeto de lo enunciado en tanto historia ficticia.

Aunque algunos teóricos de la autobiografía han enfatizado que los textos autobiográficos se ciñen a ciertas normas de escritura, Rosario Castellanos no se adhiere a estas formas, más aún cuando su intención no es que el lector reconozca a la autora en los personajes. Sin embargo, en Rito de iniciación encontramos varias correspondencias entre el personaje de Cecilia y Rosario Castellanos:

* A manera de disfraz, encontramos que las iniciales del nombre y 
apellido de la protagonista corresponden a la inversa con los de la au-

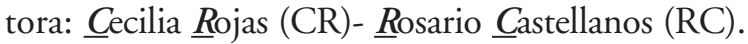

* Rosario Castellanos llega de Chiapas a la ciudad de México en 1939, es decir a los catorce años, hace el último año de secundaria y el bachillerato, en la universidad ingresa a Jurisprudencia y posteriormente a Filosofía. El personaje de la novela llega a la ciudad, se inscribe en Historia y después pasa a Letras.

* En 1971, Elena Poniatowska recoge el testimonio de Rosario sobre la aceptación de las mujeres en el ambiente universitario de los años cuarenta, según su propia experiencia. Como en el caso de su personaje, "uno tenía que hacerse la tonta para tener una relación amistosa con los compañeros. No toleraban la más mínima competencia [...] en aquella época los hombres tenían una concepción muy medieval respecto de lo que debería ser una mujer" (Poniatowska 2004: 12-15).

Dice la propia Elena Poniatowska que la obra de Rosario Castellanos como ninguna otra "está tan ligada a la vida, ninguna tan clara, tan rica en información personal” (Argüello Díaz 1981: 136). Es en este sentido que el análisis autobiográfico que propongo de algunos textos narrativos de la autora, se basan en una "intratextualidad", entre la vida (realidad) y la escritura literaria (ficción). A lo largo de su producción narrativa, Castellanos retoma algunos sucesos de su vida y los traslada a la literatura, pero siempre utilizando la "interpósita persona". ${ }^{1}$ En 1950, Rosario Castellanos publica en la revista América el cuento "Primera revelación" que sería el génesis de Balún Canán (1957). En ambos textos se puede apreciar la muerte del hermano, de quien sí proporciona el nombre - Mario- y quien en el referente real llevó el nombre de Mario Benjamín. En Balún..., además, el padre de la protagonista y el de la autora comparten el mismo nombre - César- Tanto la muerte del hermano y el dolor de los padres por lo acontecido, marcan a la niña protagonista (sin nombre) de Balún Canán así como a la propia Castellanos. En su carta del 15 de agosto de 1950, la autora le dice a Ricardo Guerra:

Usted sabe que tuve un hermano y que se murió y que mis padres, aunque nunca me lo dijeron directa y explícitamente, de muchas maneras

${ }^{1}$ Por interpósita persona George May entiende el distanciamiento entre el autor real de la ficción y los personajes, es decir, que el autor de un texto autobiográfico no se compromete como personaje ni pretende que su público lo asocie con éste. 
me dieron a entender que era una injusticia que el varón de la casa hubiera muerto y que en cambio yo continuara viva y coleando. Siempre me sentí un poco culpable de existir; durante todos esos años hubiera querido pedir perdón a todos por estar viviendo y me sentía yo culpable en cierto modo de que las cosas hubieran sucedido de ese modo y no del otro que ellos deseaban (Castellanos 1994: 35-36).

Este acontecimiento es calificado por la autora como "una raíz amarga y difícilmente extirpable" (Castellanos 1994: 36). Si "Primera revelación” y Balún Canán son dos textos autobiográficos que coinciden con la infancia de Rosario Castellanos: la muerte de Mario Benjamín y el reparto agrario del Presidente Lázaro Cárdenas — que arruinó anímica, social y económicamente a la familia Castellanos Figueroa, el relato "Tres nudos en la red", publicado en Revista de la Universidad de México en 1961 también se convierte en un texto autobiográfico de la adolescencia y juventud de la autora: en el argumento se enfatiza nuevamente - como en Balín Canán y otros textos-, la mala relación entre los padres. En este caso, el personaje de Esteban Sanromán — padre de Águeda, la protagonista de la historia-, se ve obligado a abandonar Comitán, Chiapas, junto con su familia como consecuencia a la decadencia económica que les trajo el cardenismo. La emigración hacia la capital del país le permite a Águeda ingresar a la universidad, estudiar la carrera de Derecho - después de haber declinado los estudios de química, sugerencia de su padre- . Una de las coincidencias entre vida y literatura autobiográfica más marcadas es la enfermedad de Juliana, ${ }^{2}$ madre de Águeda. Al final del relato, cuando los estudios y el trabajo de la protagonista le permiten llevar una vida independiente en lo económico, Juliana abandona la casa familiar y se interna en el Pabellón de Incurables del Hospital de Cancerología. Este acontecimiento coincide en un nivel extraliterario con la muerte de Adriana Figueroa Abarca — madre de Rosario Castellanos, quien muere en 1948 víctima de cáncer en el estómago.

Una de las características de la obra narrativa de Rosario Castellanos en relación con los personajes femeninos es que las mujeres transgresoras de provincia son doblemente castigadas por el núcleo familiar y social, quienes imponen las formas de vida que se tienen que seguir para no ser despreciadas. Para una mujer solterona, estéril o "inmoral",

\footnotetext{
${ }^{2}$ Nótese la similitud fonética entre Juliana (ficción), y Adriana (referente real de
} la madre de Rosario Castellanos). 
la sociedad le tiene reservada la burla y el desprecio inmediato. Para soportar la exclusión y llegar a la independencia afectiva y económica es necesario salir de un espacio donde se les condena; sirvan como ejemplo "la Estambul" o "la Casquitos de venado" del cuento "Los convidados de agosto". La primera sale de Comitán y vuelve años más tarde convertida en torera —oficio generalmente masculino-, la segunda es una madre soltera que por necesidad busca la suficiencia económica en la costura; ésta última, advierte el narrador del relato, es despreciada por los comitecos, incluso no recurren a sus servicios como muestra de castigo.

En Rito de iniciación tanto Cecilia como su tía Beatriz — quien tuvo que abandonar un espacio donde la soltería es condenada-, encuentran en la cuidad de México una forma de realización o la tranquilidad de saberse aunque despreciadas, seres más libres. A diferencia de otras "solteronas" 3 de Rosario Castellanos, Beatriz es una mujer más libre e independiente en cuanto a lo económico y afectivo; la herencia de sus padres le permite huir hacia la ciudad, aunque sin otras aspiraciones que el recogimiento y la tranquilidad personal. Por el contrario, Cecilia encuentra en la universidad la iniciación a una vida más compleja que le ofrece no repetir los mismos patrones que su tía: la soltería como oficio. La emigración del campo hacia la ciudad es para Cecilia un acto de liberación que le permite incorporarse y descubrir otro modo de ser independiente. Cuando hace los trámites para ingresar a la carrera de letras — después de haber declinado la de historia-, el primer integrante del grupo con el que se iniciará en la vida intelectual de la Facultad es Sergio del Castillo. La autora de Rito de iniciación presenta al personaje de Cecilia como una joven provinciana ignorante que "huye" de la provincia después de una decepción amorosa. Si bien es cierto que en sus primeros pasos en la capital, Cecilia aparece como un ser manipulable, inexperto, anónimo, débil y con un bagaje cultural y literario deficientes; en la provincia es considerada un ser anormal, diferente a las demás jóvenes de su edad y transgresora, pues el

${ }^{3}$ Dice Rosario Castellanos sobre la soltería: "Quedarse soltera significa que ningún hombre consideró a la susodicha digna de llevar su nombre ni de remendar sus calcetines. Significa no haber transitado jamás de un modo de ser superfluo y adjetivo a otro necesario y sustancial. Significa convertirse en el comodín de la familia. ¿Hay un enfermo que cuidar? Ahí está fulanita que no tiene obligaciones fijas" (1998: 880). 
pensar en los estudios universitarios y la lectura por encima del noviazgo, el matrimonio y la maternidad, la presentan ante los otros como un personaje que posee una conciencia genérica sobre el trato hacia las mujeres de su medio, así como la forma en que ellas se piensan a sí mismas y a las demás. La estancia en la capital y en la Facultad, le permiten conocer-descubrir e iniciarse en la vida amorosa, sexual e intelectual. Esta última iniciación parece que es la más prometedora y placentera ya que las anteriores se traducen como un desencanto crítico y doloroso del ser, además de que al final de la novela se dan como pérdidas.

Entre Sergio y Cecilia hay una identificación subjetiva: ambos se asumen como "entes marginales"; el primero por ser homosexual y Cecilia por poseer el don de la palabra. En el capítulo diez, Sergio le propone matrimonio con el fin de disfrazar lo que llama "un pequeño defectito" (335); su ingreso al mundo intelectual no le impide seguirse preocupando por satisfacer a su núcleo familiar y social, más aún cuando ve en los estudios un fin utilitario que le proporcionará éxito: "Quiero el éxito, el prestigio, el dinero, el poder" (355). Si la protagonista no piensa en el matrimonio y la maternidad como sinónimos de realización femenina, Sergio en cambio, sí piensa en cumplir su rol genérico que le proporcionaría prestigio y estabilidad.

Cecilia busca comprender ciertos problemas de la vida, la necesidad que tiene por traducir los acontecimientos en imágenes le augura una práctica literaria. Esta concepción que tiene el personaje de escribir para comprender es la misma inquietud de Castellanos: "Escribir ha sido, más que nada, explicarme a mí misma las cosas que no entiendo" (Carballo 1982: 513).

Rosario Castellanos retoma a su personaje de Rito de iniciación en el relato "Historia mexicana: un exilio" publicado en su columna de Excélsior el 24 de julio de 1966. En este relato sólo se plantean aspectos del primer capítulo de la novela. Lo que se enfatiza es la "anormalidad" de Cecilia, sus inquietudes e inclinaciones hacia los estudios universitarios, el deseo de salir de un espacio donde a las mujeres se les inhibe todo proyecto de vida que se aleje de lo impuesto por un mundo ajeno a las aspiraciones de ella. Dice la voz narrativa de este relato:

Era anormal. No es que hubiera nacido con seis dedos en los pies, ni que se hubiera enamorado de un asno, de un pavorreal ni de alguna de 
sus compañeras de juegos... Era que hablaba. Y decía todo lo que se le ocurría y se le ocurrían cosas que no se les ocurrían a los demás. No, incoherencias no. Rarezas, asociaciones peregrinas de ideas, comparaciones ridículas de figuras, calificativos exactos de hechos. Cuando se callaba era sólo porque estaba madrugando alguna barbaridad (Castellanos 1974: 48-49; las cursivas son mías.)

Una de las variantes entre la novela y el relato es que en éste último, el noviazgo con Enrique - un joven también provinciano con un patrón de conducta de filiación machista-, es presentado como un sacrificio por parte de él. Cuando Cecilia decide abandonar el pueblo y sustituir el noviazgo por los estudios, la gente le dice al joven: "Ay Enrique, si es cierto que te sacrificaste, tu sacrificio resultó vano. Mírala cómo se va, fachendosa y soberbia, a estudiar a México" (1974: 51).

La referencia al noviazgo con Enrique que hace Cecilia en Rito de iniciación ocupa el primero y segundo capítulo. El narrador de la novela dice: "Porque Enrique, como todos los compasivos, prolongó la agonía de su víctima con el silencio. Y no se atrevió a rematar a Cecilia sino que huyó de ella como un culpable" (16). El Enrique-Eneas es presentado en la novela como un joven cruel. Le recrimina a Cecilia: “- ¿Por qué me persigues, me espías, me acosas? ¿Es que no puedo dar un paso sin que te arrastres detrás de mí?” (17). Si en la relación amorosa la protagonista de la novela es víctima del abandono, los malos tratos y hasta la compasión; la conciencia de género en Cecilia la lleva a salir de un espacio y estados enajenantes. Entre la pareja de novios se crea una rivalidad en cuanto a las ideas; ella escribe-crea (cartas y diario íntimo), él no puede contestar porque es incapaz de escribir-crear. Esta rivalidad produce miedo e incompetencia en Enrique, mientras que en Cecilia se crea la culpa ${ }^{4}$ y una soledad constante que no logra mitigarse a lo largo de toda la novela: "Enrique, se alejaba de ella, como los

${ }^{4}$ La culpa es un sentimiento que aparece de manera muy constante en los textos narrativos de Rosario Castellanos: En "Primera revelación” y Balún Canán, la niña protagonista siente culpa por la muerte del hermano, en Oficio de tinieblas, y en la novela corta El viudo Román, las protagonistas también experimentan este sentimiento. La propia Rosario Castellanos muestra en varias de sus cartas a Ricardo Guerra el sentimiento de culpa por algunos acontecimientos de su vida: la muerte de su hermano y posteriormente la de sus padres, además de atribuirse la responsabilidad de los problemas conyugales frecuentemente. 
otros, por miedo" (18). El rechazo de Enrique es hacia los proyectos e inclinaciones literarias de la joven cuya arma es la palabra.

Rosario Castellanos abandonó Chiapas a los catorce años para trasladarse a la ciudad de México donde continuaría sus estudios. ${ }^{5}$ Este cambio de escenarios (provincia-capital) le permitió ingresar a la universidad donde conocería a la futura generación del medio siglo. ${ }^{6}$ En la universidad, Castellanos declina los estudios de Derecho por los de Filosofía, mientras que la protagonista de la novela cambia la carrera de Historia por la de Letras. Dice Castellanos en Los narradores ante el público: "Mientras me debatía en estas perplejidades, una persona a la cual deseaba complacer, me aconsejó el estudio de la filosofía, disciplina para la que — -según él- tenía aptitudes especiales. Seguí el consejo y no me arrepiento" (Castellanos 1966: 93). ${ }^{7}$ En Rito de iniciación, la persona que convence a Cecilia para que estudie Letras es Sergio del Castillo. En la novela se advierte que la carrera de Historia la estudian las mujeres. En el caso de Cecilia, dicha carrera no se traduce como el saber por el saber, sino por el deseo que tiene la joven de indagar sobre su existencia y la historia de su pueblo. Si bien es cierto que en la época de Cecilia, las jóvenes ya no estudian "piano, pintura a la acuarela y bordados" (78), la idea que la protagonista tiene de la historia está en

${ }^{5}$ Rosario Castellanos estudió el Bachillerato en Derecho y Ciencias Sociales. Se certificó el 22 de noviembre de 1943. En el certificado de bachillerato, se pueden ver las buenas calificaciones de la estudiante. Su calificación más baja fue (Nueve) en la asignatura de Español, materia que cursó en el segundo año de Preparatoria. En certificado de secundaria se asienta que el primer año lo cursó en la Escuela Helena Herlihy Hall en 1939; el segundo año en la Escuela Secundaria de Comitán, Chiapas, en 1940. El tercer año lo cursó ya en el Colegio Luis G. León con domicilio en la colonia Roma Sur en el D. F. (Expediente de Rosario Castellanos Figueroa núm. 1944/49126, consultado en la Subdirección de Certificación y Control Documental de la UNAM, marzo de 2005).

${ }^{6}$ Marco Antonio Puig Albores asegura que algunos jóvenes a los que Castellanos conoce en la universidad y que aparecen el las páginas de Rito de iniciación son una "literaturización" del grupo llamado "Ocho poetas" (Entrevista realizada en enero del 2003 en Comitán, Chiapas). Existe una antología titulada Ocho poetas publicada por Alfonso Méndez Plancarte.

${ }^{7}$ El 18 de febrero de 1944, Rosario Castellanos solicita su inscripción a la Escuela de Jurisprudencia para cursar el primer año de la carrera de Derecho. El 23 de febrero de 1945, Castellanos presenta una solicitud de reingreso a la carrera de Filosofía en la Facultad de Filosofía y Letras (Expediente de Rosario Castellanos Figueroa 1944/ 4126). 
función de conocer sus orígenes, para entender la genealogía familiar, su posición de dominio económico y social. Como en el caso de los Argüello en Balún Canán, Cecilia habla de unos papeles que son la herencia de sus antepasados y que dan evidencia de la forma de vida de una época pasada, dichos documentos están en poder de su padre (en Balún Canán son la herencia de Mario).

Por otro lado, las coincidencias de Rito de iniciación con otras novelas de Castellanos aparecen en lo que denomino expansión temática. En el capítulo cinco el narrador dice:

Cecilia era hija única. Por lo menos, desde que tenía memoria, porque más allá hubo una atmósfera de la que se conservó la sensación oscura de duelo por algún hermano muerto, de nostalgia por alguna criatura nonata. Algo de esa atmósfera impregnaba aún los actos de su madre -inopinados, bruscos, doloridos-y sus palabras, que acostumbraban como a detenerse en el brocal de un pozo cegado (89).

Esta referencia autobiográfica al hermano muerto y al dolor de la madre, es un tema obsesivo para la autora quien además de llevarlo a la literatura lo refirió en entrevistas y cartas (no ficticias). María Escandón, la niña compañera de juegos en la infancia de Rosario también está presente en la novela: "Cecilia tuvo a su merced pequeñas siervas sobre las cuales era una costumbre ejercer el capricho, el poder y la crueldad con todo lo que de exagerados tienen estos atributos... Actuaba y contemplaba la humillación ajena con la misma indiferencia del que contempla un objeto de calidad corriente y de uso cotidiano" (89). Escribe Castellanos en 1973 en una de sus columnas de Excélsior:

...el hijo de los patrones tenía para entretenerse, además de sus juguetes que no eran muchos y que eran demasiado ingenuos, una criatura de su misma edad. Esa criatura era, a veces compañera con iniciativas, con capacidad de invención... Pero, a veces también, era un mero objeto en que el otro descargaba sus humores: la energía inagotable de la infancia, el aburrimiento, la cólera, el celo amargo de la posesión (1974: 262).

Por otro lado, la relación matrimonial difícil entre los padres de Cecilia, también es un elemento intertextual en varias obras de Castel- 
lanos. En Balún Canán, Zoraida - la esposa de César-, es una mujer frustrada como madre y esposa. Vive con un hombre recalcitrante y veinte años mayor que ella. En "Tres nudos en la red" y El viudo Román las virtudes femeninas de las mujeres son: padecer la frustración en silencio y el respeto hacia el esposo. En Rito... el caso de doña Clara y José María es muy parecido: ella acepta la propuesta de matrimonio para pertenecer a una familia respetable, tiempo después las riquezas de José María comienzan a mermar, con frecuencia discuten y ella no entiende las conversaciones de él (se aburre). ${ }^{8}$ En la novela póstuma de Castellanos también se hace referencia como en Balún Canán al conflicto cristero. Escribe Cecilia a su padre:

Cuando yo era muy pequeña, y mi curiosidad carecía aún de discernimiento, te preguntaba por qué mi madre iba a la iglesia y rezaba y recibía los sacramentos... estos acontecimientos coincidieron con la persecución religiosa decretada por el Gobierno y que tú consideraste atentatoria a los derechos y a las libertades inalienables de los individuos. Y, perseguida, la religión se convertía en una actividad secreta [...] (64).

A lo largo de las páginas de la novela, el lector puede advertir una conciencia crítica y despiadada que enjuicia los actos de la protagonista como en un juego de espejos. ${ }^{9}$ Estos juicios son emitidos por la otra

\footnotetext{
${ }^{8}$ Dice Lolita Albores: "Rosario y su papá se entendían muy bien cuando hablaban de escritores y de política, leía cada uno su periódico y cambiaban opiniones; doña Adriana quedaba aislada y por eso cuando yo estaba con ella se sentía contenta de tener con quién hablar de cosas más sencillas" (3). La versión de Castellanos es opuesta.

En Cartas a Ricardo anota: "Con mi mamá pude todavía reconciliarme tres años antes de su muerte, comprendí su sufrimiento, su situación de inferioridad en la casa por el hecho de que ella pertenecía a una familia pobre... Que se había casado sin amor, por miedo a la pobreza, con un hombre veinte años mayor que ella y lleno de manías y de conceptos equivocados sobre su propio valor, sobre la obligación que tenían los demás de rendirse a su voluntad... Eso fue lo que no pude perdonarle a mi papá; su crueldad, su incomprensión, su falta de flexibilidad para tratarla a ella que era como una criatura sensible y afectuosa" (36).

${ }^{9}$ Los espejos en la narrativa y la poesía de Rosario Castellanos aparecen de manera constante, generalmente denotan un rechazo de género y por lo tanto existencial, son una tortura psicológica. Los espejos son un juez inapelable que no tiene compasión; reflejan el miedo y la soledad de quien se mira en ellos. En particular los personajes
} 
Cecilia (la conciencia) quien insiste en la incapacidad que tiene la otra para relacionarse con la gente. La conciencia de la protagonista la margina, le crea inseguridad y le afianza el complejo de fealdad. En el capítulo tres, las dos Cecilias establecen un diálogo; la conciencia minimiza la inteligencia de la otra, además de que enfatiza que la virginidad es un defecto, una tragedia y no una virtud: "Ni eres pura ni eres bonita. $\mathrm{Y}$ respecto a esto último, no voy a recurrir, tampoco, a razones de índole abstracta porque eres singularmente insensible a ellas. Pero voy a decirte que te expones al ridículo cada vez que te preocupas por lo que tú llamas, como en las revistas de moda, tu arreglo personal" (58).

La iniciación-modificación de Cecilia le permite al final de la novela separarse de la Cecilia-conciencia que atormenta, minimiza y reprocha aspectos de su vida afectiva e intelectual. El primer intento de creación textual de Cecilia asimila a tres tipos de mujeres: la prostituta de burdel, la enfermera servil que ayuda a la recuperación de un paralítico y al final son felices, y la joven universitaria que conoce a un hombre que la rescata del peligro. Los personajes y temas que elige la protagonista, así como el tratamiento que pretende darles tienen como objetivo ridiculizar las propias incapacidades de Cecilia; una mujer que escribe sobre otras mujeres que sí logran la "felicidad", aunque es cierto que todas están a la voluntad de un hombre que decide por ellas y que sólo a través de él pueden conseguir la anhelada felicidad.

En el ambiente universitario de la Facultad de Filosofía y Letras de la UNAM (antiguo edificio de Mascarones) Cecilia establece una relación si no de amistad, sí en un sentido intelectual con sus compañeros de clase. Las discusiones entre los jóvenes de este grupo giran en torno a la literatura universal y a la historia de México, siempre desde una visión crítica. En estas conversaciones Cecilia permanece constantemente en un "estar" mudo y anónimo; pocas veces puede establecer una conversación con los otros (los que "saben”). Para enfatizar la moral provinciana y conservadora de Cecilia, en el capítulo siete titulado "Erótica", la protagonista pide prestado su cuaderno de notas a Lorenzo "el desventuradillo"; aquí encuentra un relato donde se narra el apareamiento de dos animales. La creación textual de Lorenzo alarma a Cecilia quien interpreta que el cuento de su compañero es una invita-

femeninos en la narrativa de Castellanos que se miran en los espejos, o les rehuyen o los rompen. 
ción al sexo. Entre el grupo de compañeros, la protagonista establece una relación sentimental con Ramón Mariscal quien al final de la novela consigue una beca para estudiar en el extranjero. A diferencia de los personajes femeninos que Cecilia crea, ésta no puede retener a Ramón, por lo tanto la anhelada felicidad no llega. Aunque la protagonista fracasa en lo sentimental, en lo intelectual hay una progresión. Si inicialmente aparece ante sus compañeros como un ser anónimo, callado, que desconoce los temas que se discuten, en el capítulo diez puede hablar con Matilde y las demás escritoras bajo otra visión más crítica y conocedora tanto a nivel de escritura como de experiencia humana y femenina.

No son pocos los personajes femeninos de Rosario Castellanos que escriben; sin embargo, las mujeres que lo hacen generalmente viven desde la soledad, la culpa, la soltería, el miedo, la frustración y el fracaso. En un orden cronológico, encontramos la pieza dramática Tablero de damas publicada en la revista América en 1952. Castellanos utiliza la farsa para ridiculizar a varias poetisas de diversas edades, con conceptos distintos sobre la escritura. La mayoría de estas mujeres escriben por vanidad, esperan ser admiradas y reconocidas por su público. Las acotaciones de la obra enfatizan-ridiculizan el estado civil (soltera, casada, divorciada) y la edad que aparentan-niegan este grupo de escritoras. La única que ha logrado el reconocimiento es Matilde Casanova quien declara que la escritura exitosa sólo se obtiene si se renuncia al matrimonio y a la maternidad, de lo contrario - le dice a Aurora, la escritora más joven: "Serías una escritora mediocre, pero una mala esposa y una peor madre" (1998: 317). La mujer que escribe fue un tema que siempre interesó a Castellanos: como uno de los muchos ejemplos tenemos a Mujer que sabe latín... (1973), que es un homenaje de Rosario Castellanos a escritoras europeas, latinoamericanas, norteamericanas y mexicanas; sin embargo, las mujeres que escriben en los textos de ficción de Castellanos, salen muy mal libradas en su mayoría.

Otros textos donde aparecen personajes femeninos que escriben son "Primera revelación" y Balún Canán. En este caso, la niña protagonista escribe el nombre de su hermano muerto en varios espacios de la casa, pero la escritura sólo response al sentimiento de culpa y no al hecho literario. En el cuento "Las amistades efímeras" del libro Los convidados de agosto (1964), la narradora-adulta cuenta desde un presente, la historia de una amiga de la adolescencia: Gertrudis, quien transgrede 
la moral comiteca al huir con un "fuereño" el mismo día de haberlo conocido. A diferencia de Gertrudis, la narradora del cuento buscó otra forma de realización femenina encontrada en la literatura como profesión y como independencia del círculo social alienable al que perteneció por tradición, pero que pudo modificar por conciencia genérica; ella misma refiere que dentro de Comitán se inclinó por la escritura, aunque esta actividad suponga la condena y el desprecio de la gente:

Porque yo estaba poseída por una especie de frenesí que me obligaba a hablar incesantemente, a hacer confidencias y proyectos... a interpretar mis sueños y recuerdos. No tenía la menor idea de lo que era ni de lo que iba a ser y me urgía organizarme y formularme, antes que con actos, por medio de las palabras" (1996: 717; las cursivas son mías).

Sobre las mujeres de provincia, la narradora-escritora del relato enfatiza las especies diferentes y por lo tanto los caminos elegidos o impuestos, la necesidad de salir hacia otros espacios no tan condenables y más autónomos. En un plano autobiográfico, la narradora de "Las amistades efímeras" así como los demás personajes femeninos que escriben, pueden considerarse el alter ego de la propia Rosario Castellanos que construye una historia "a través de la memoria humana y de la eternidad de las palabras" (1996: 717). El cuento "Álbum de familia" que da título al libro publicado en 1971 y que ocupa el capítulo nueve de Rito de iniciación, ${ }^{10}$ plantea desde la narrativa la misma situación

${ }^{10}$ No es mi intención abundar en el presente trabajo sobre los anacronismo de la novela, sin embargo considero pertinente señalar que el ingreso de Cecilia a la universidad se da a finales de la década de los cuarenta. En el capítulo diez, al hacer las reflexiones sobre el quehacer poético femenino, el grupo de escritoras reunidas, refiere tres Premios Nobel para Hispanoamérica; aunque sólo se menciona el caso de Gabriela Mistral en 1945. Los dos premios restantes fueron para Miguel Ángel Asturias en 1967 y para Pablo Neruda en 1971. Dice Eduardo Mejía en sus comentarios a Rito de iniciación que al encontrar el manuscrito de la obra, del capítulo "Álbum de familia” sólo se encontraba el título. Lo anterior supone que la autora modificó el texto para publicarlo como un cuento independiente de la novela en 1971. Otro dato que afianza mi observación es que el voto a la mujer mexicana se concede en 1953. En la ficción se dice que Matilde y Victoria han estado fuera de México por varios años y aunque es inadmisible que Victoria no esté enterada del derecho al sufragio femenino en México, al hablar de la libertad de las mujeres con la reportera, pregun- 
que Tablero de damas, sólo se modifican los nombres de algunas escritoras. En este cuento, las condiciones en las que se desenvuelven las mujeres que escriben son más difíciles que en la pieza fársica: Amita Jordán es una escritora que ha tenido que recurrir a la prostitución para conseguir la fama, el poco talento de Victoria, sólo le permite convertirse en la secretaria de Matilde Casanova - la poetisa que obtiene el Premio de las Naciones-, Josefa Gárdara tampoco ha conseguido sobresalir en el mundo de las letras, mientras que Elvira Robledo es una mujer divorciada, frustrada en lo conyugal e intelectual. Como se puede observar, las mujeres escritoras de Castellanos pretenden justificarse a través de sus textos, aunque sólo Matilde ha conseguido el reconocimiento; todas presentan conflictos individuales, están insatisfechas y frustradas, incluso Matilde, quien al ser estéril experimenta una culpa obsesiva; su escritura aunque sólida no ha logrado darle sentido a su existencia.

Dice Arnold Van Gennep en su libro Ritos de paso, que los ritos de iniciación en cualquier tipo de sociedad consisten en pasar sucesivamente de una edad a otra y de una ocupación a otra, mediando la descomposición, la separación, la agregación o la modificación de una forma de vida a otra de una manera pasajera. La iniciación intelectual de Cecilia sólo se puede dar cuando abandona el espacio familiar y social que le inhibe toda posibilidad de liberación e independencia. El mundo de las letras le permite crear y hablar desde una conciencia personal. La estancia en la capital, los estudios y el ambiente universitario, suponen una metamorfosis liberadora en lo intelectual, no así en lo afectivo que se traduce como una frustración. El pasado y el presente de Cecilia no se modifican; los estudios no le han presentado la opción de ser más feliz, pero sí le permiten hacer un "rito de despedida" que le autoriza un nacimiento a la escritura. En el capítulo diez de la novela, Cecilia hace una reflexión acerca de los libros que "usurpan, a veces, las funciones del amado ausente" (311). Este comentario supone que la escritura le permite a Cecilia transformarse de un ser

ta: “¿Podemos siquiera votar? (248). Por su parte, en el capítulo cuatro, Sergio le pregunta a Cecilia: "Usted es de las que quieren tener derecho al voto ¿no?” (74). Aunque este desfase temporal no afecta a la diégesis de la obra, es importante señalar que la novela es una evidencia de la participación de la mujer en la vida intelectual del país desde finales de los cuarenta hasta 1971, año en que se sitúa el capítulo diez. 
anónimo e intrascendente a otro público y prometedor. Este capítulo con matices líricos muy marcados, es un acto de despedida tanto de los lugares físicos como de personas; dice Cecilia: "Si he de acostumbrarme a la soledad más vale que empiece ahora" (357). La frase anterior anuncia la separación de un mundo malsano y el segundo nacimiento a un universo aunque incierto, diferente. De manera muy marcada, el capítulo "Álbum de familia" se abre con el sueño turbulento y extraño que tiene Cecilia en aras de la recepción que dará Matilde Casanova:

El mar se había batido la noche entera contra la oscuridad y Cecilia, entre sueños, había soñado que alguna vez las olas se detenían en ese límite en el que ¿por qué? abandonaban su fuerza para comenzar a retroceder, como arrepentidas del ímpetu que las había llevado tan lejos, sólo para arrepentirse de su arrepentimiento y volver a comenzar (239).

El sueño cuyas imágenes son la turbulencia y la oscuridad, sugieren el desengaño, la modificación y la renuncia a una forma de vida anterior, también anuncia el nacimiento de una joven escritora. La frase metafórica que cierra el cuento "Cuarta vigilia" y Oficio de tinieblas: "Faltaba mucho tiempo para que amaneciera" (para las mujeres y los indios), ahora la vemos en Rito de iniciación desde otra perspectiva: el rito de despedida que hace la protagonista le ocupa un tiempo que va de la noche a la madrugada. Los espacios abiertos (las calles), así como el amanecer, sugieren que el destino inmediato de Cecilia será diferente al de otros personajes femeninos de Rosario Castellanos.

Con Rito de iniciación, Castellanos presenta que hay otras opciones para la realización de la mujer. Cecilia es capaz de rechazar y cuestionar las opciones de vida que se le ofrecen; no piensa en asumir el "rango de señora”, sino el de mujer de letras-ideas. El monólogo interior del último capítulo presenta a una figura femenina con poder (para hablar y escribir) aunque desvalorizada en lo afectivo y marginada. Aunque su futuro es incierto en lo personal, Cecilia sabe que tendrá que asumir su doble condición: la de mujer y escritora.

Con Rito de iniciación, Rosario Castellanos estaba hablando de sí misma, las problemáticas de su personaje fueron en gran medida las de ella misma y las de otras mujeres intelectuales de su generación que tuvieron que luchar en el ambiente literario predominantemente masculino. Por época y personaje, Rito de iniciación se corresponde con la 
etapa de adolescencia/juventud de Castellanos. Al igual que su protagonista, la autora tomó la pluma como una profesión, una forma de vida y una herramienta para comprender y comprenderse. Las correspondencias entre autora y personaje, nos hablan de una necesidad de Castellanos por ir trazando etapas importantes en su vida, de hablar de ella misma, aunque a través de una novela autobiográfica.

\section{BibLIOGRAFíA}

Albores, Lolita. "Sí conocí a Rosario Castellanos", en Imaginarte a Comitán. Publicación sobre el pasado, presente y futuro de Comitán y la Región Fronteriza de Chiapas (2da. quincena de agosto de 2002).

Castellanos, Rosario. Cartas a Ricardo. Prólogo de Elena Poniatowska. México: Consejo Nacional para la Cultura y las Artes, 1994 (Memorias Mexicanas).

- El uso de la palabra. Prólogo de José Emilio Pacheco. México: Ediciones de Excélsior, 1974.

- Los narradores ante el público. México: Joaquín Mortiz, 1966.

- Obras I. Narrativa. México: Fondo de Cultura Económica, 1996. (Letras Mexicanas).

- Obras II. Poesía, teatro y ensayo. México: Fondo de Cultura Económica, 1998 (Letras Mexicanas).

- Rito de iniciación. México: Alfaguara, 1997.

Carballo, Emmanuel. XIX protagonistas de la literatura mexicana. México: Joaquín Motriz, 1966.

- Protagonistas de la literatura mexicana. México: Ediciones del Ermitaño, 1982.

Domínguez, Luis Adolfo. "Entrevista con Rosario Castellanos", en Revista de Bellas Artes (enero-febrero de 1969).

Fe, Marina (coord.). Otramente: lectura y escritura feminista. México: Fondo de Cultura Económica, 1999 (Lengua y Estudios Literarios)

Gennep, Arnald Van. Ritos de paso. Madrid: Taurus, 1986.

Heuser, Carmen. "Los rastros del recuerdo", en Autobiografía y escritura. Juan Orbe (comp.). Buenos Aires, Corregidor, 1994.

Lejeune, Philippe. Le pacte actibiographique. París: Seuil, 1975.

May, George. La autobiografía. México: Fondo de Cultura Económica, 1982 (Breviarios).

Poniatowska, Elena. Ay vida, no me mereces. México: Era, 1986. 